\title{
Editorial: The 'Universal' Declaration of Human Rights
}

In 1948 the United Nations General Assembly adopted what was called the Universal Declaration of Human Rights. The declaration was and is a worthy document, full of decent sentiment and high aspiration. In its day it was an attempt to establish a new dispensation for all people, everywhere, out of the ashes of the Second World War.

But, in what sense was it universal? Even in 1948 it was not universally agreed to. In the General Assembly of the day a number of countries abstained on it, including significantly the USSR, South Africa and Saudi Arabia.

Even less was it universally implemented, which remains the case in 2017. Lack of universal implementation is hardly surprising as the rights declared include freedom of expression, freedom of religion and the freedom to change religion, freedom to marry whom one choses, free education, freedom of association, gender equality and also the guarantee of food, clothing, housing and medical care, security against unemployment, sickness and disability and even a right to holidays. Only the richest and most liberal countries could come close to meeting these demands.

But it is not just lack of means that is the problem. During the years since its adoption voices have been heard claiming that the 'universal' declaration was actually an expression of a Western view of how life should be lived, and of what rights there are. We philosophers might jib at this sort of criticism. After all, can we not produce rational arguments to support what is in the declaration, arguments which, in full Kantian mode, ought to command the assent of all rational beings?

That, of course, is the crux of the matter. There are large swathes of the world where people do not accept some of the key rights, or certainly not as they might be interpreted in philosophical or legal circles in New York or London. Is this disagreement necessarily a symptom of bad faith or of irrationality on the part of those who reject some of the rights?

Or is it rather that the diet of rights encapsulated in the Universal Declaration actually is a product of a particular tradition, as critics are continuing vociferously to claim in 2017? If we were honest, we would have to admit that the thinking and practice which inspired 


\section{Editorial}

the Universal Declaration is one that emerged from a long European tradition, with its roots in Greece and Rome, and owing much to developments in Christianity and the Enlightenment. We could go on to argue that it would be a good thing if everyone could be persuaded to adopt what we might have to call 'our' view, so that it did indeed become universal, in the sense of being universally agreed to, and perhaps too that they ought to be universally agreed to.

But if, for the best of reasons (as we might see it) we do that, we need to confront the question raised by Nietzsche more than a century ago about George Eliot and the English atheists. Having got rid of the Christian god, they feel that they must cling more firmly to the Christian morality, yet that morality is by no means self- evident: so, how sustainable is that morality and what it underpins when cut off from its sustaining roots? How universal are its implications?

Precisely because we are in an increasingly global arena of public discourse and controversy, these questions are now taking on a fresh urgency, practical as well as philosophical. It is for this reason, among others, that the recent inauguration of Oxford University's Bonavero Institute of Human Rights is very timely. As philosophers, we should accord it a warm welcome. 